\title{
A new species of Stethelmis Hinton (Coleoptera: Elmidae) from Argentina and description of its larva
}

\author{
NICOLÁS RAFAEL MARTÍNEZ-ROMÁN ${ }^{1}$,VERÓNICA MANZO $^{2}$ and MIGUEL ARCHANGELSKY ${ }^{1}$ \\ ${ }^{1}$ Laboratorio de Investigaciones en Ecología y Sistemática Animal (LIESA), CIEMEP \\ (CONICET-UNPSJB) Roca 780, C.P. 9200 Esquel, Chubut, Argentina \\ ${ }^{2}$ Instituto de Biodiversidad Neotropical (IBN), UNT-CONICET, Crisóstomo Álvarez \\ 722, San Miguel de Tucumán C.P. 4000, Tucumán, Argentina \\ Manuscript received on September 11, 2018; accepted for publication on January 29, 2019
}

\begin{abstract}
How to cite: MARTÍNEZ-ROMÁN NR, MANZO V AND ARCHANGELSKY M. 2019. A new species of Stethelmis Hinton (Coleoptera: Elmidae) from Argentina and description of its larva. An Acad Bras Cienc 91: e20180954. DOI DOI 10.1590/0001-3765201920180954.

Abstract: A new species of Stethelmis, S. shepardi sp. nov., is described for Patagonia, Argentina from adults of both sexes. A full description and illustrations of both the adult and the larva of the new species are provided with comments on its habitat and distribution. Adults of the new species are compared with those of S. kaszabi (Hinton 1970) and S. chilensis (Hinton 1945). The larva of S. shepardi is compared with that of S. kaszabi, the other Stethelmis larva described. We also describe and illustrate for the first time the male genitalia of S. kaszabi. A key to the known species of Stethelmis is also included.
\end{abstract}

Key words: Elminae, Neotropical, Patagonia, Riffle beetles, Stethelmis shepardi.

\section{INTRODUCTION}

Stethelmis Hinton is an endemic elmid genus of the Neotropical region, restricted to the southern region of Chile and Argentina (Archangelsky and Manzo 2007, Manzo 2013) and belongs to the subfamily Elminae. There are only two described species: S. chilensis (Hinton 1945) from Chile and S. kaszabi (Hinton 1970) from Argentina. S. kaszabi has been cited for the argentine provinces of Río Negro (Hinton 1970) and Chubut (Archangelsky and Manzo 2007, Manzo and Archangelsky 2014). For $S$. chilensis no locality details were provided in the original description, but recently Solervicens Alessandrini (2014) cites this species in the national

Correspondence to: Nicolás Rafael Martínez-Román

E-mail: martinezroman@comahue-conicet.gob.ar

ORCid: https://orcid.org/0000-0001-6630-1832 reserve Río Clarillo, in the Metropolitan Region of Santiago, Chile. While $S$. chilensis larva remains unknown, the larva of $S$. kaszabi was described by Archangelsky and Manzo (2007).

In several field trips to the locality of Corcovado and near the town of Esquel, some unidentified elmid adults and larvae presenting the diagnostic characters of Stethelmis's were collected. Adults show tomentum on abdominal ventrites; pronotum without sublateral carinae, transverse procoxae with trochantin externally visible and toothed tarsal claws; larvae feature a slightly flattened body, anterior margin of head capsule with a tooth between base of antenna and clypeus, procoxal cavities open and pleural sclerites on abdominal segments I-V. The adults resemble those of $S$. kaszabi but the genitalia is notoriously different 
and differences in body surface punctuation and in the extension of tomentum are also evident. On the other hand, larvae associated with these adults differ mainly from those of $S$. kaszabi in that larvae of the former have very characteristic dorsal gibbosities on the abdomen and the frontal teeth of the head are less prominent. Likewise, both larvae and adults of this morphospecies occupy very different habitats than those of $S$. kaszabi and do not coexist in the same sector of a creek/river. This made us conclude that the individuals collected belong to a new Stethelmis species. Here, we describe and illustrate this new species of Stethelmis and its larva and compare them with the adult and larva of S. kaszabi and adult of S. chilensis; in addition, the male genitalia of $S$. kaszabi is described since the original description of this species was based on a female (Hinton 1970).

\section{MATERIALS AND METHODS}

Adults and larvae were killed and preserved in 75\% ethyl alcohol. For habitus pictures five larvae and five adults were cleaned with an ultrasonic cleaning machine for four minutes set at 30/50 watts power (methodology adapted from (Harrison 2012)). Adults were cleared in potassium hydroxide for 48 hours (5 specimens) and legs were dissected and mounted on glass slides with Polyvinyllactoglycerol (PVLG) medium. Larval specimens were cleared in warm lactic acid (10 specimens), dissected and mounted on glass slides with PVLG medium. Observations (up to 400X) were made with a Leica MZ6 and Leica S6D dissecting microscopes and Leica DMLB and Leica DM 500 compound microscopes, the last three with a photographic camera attached. Photographs were assembled using the freeware program CombineZP (Hadley 2010). Habitus pictures were taken from dry specimens; therefore, the color is darker than that of wet specimens. For morphometric information, five to ten of each larvae and adults were measured. We follow adult morphology nomenclature of Kodada et al. (2016); for larval morphology we follow the nomenclature of Lawrence (1991) and Kodada et al. (2016). All available geographical records of the new species of Stethelmis were mapped with Q-GIS (QGIS Development Team 2017).

The type material and part of the larval specimens are deposited at the Instituto de Biodiversidad Neotropical (IBN), Tucuman, Argentina; additional larval material is held at the collection of one of the authors (M.A.).

\section{RESULTS}

\section{Stethelmis shepardi sp. nov.}

\section{DIAGNOSIS}

Adults of this new species may be distinguished from all the other known Stethelmis species by the following combination of characters: 1) areas between punctures at depressions of pronotum glabrous; 2) tomentum on epipleura reaching the first abdominal ventrite; 3 ) tomentum on abdomen covering up to the basal fourth of fourth ventrite; 4) aedeagus with median lobe broad, lanceolate and stretching near apical third; basolateral apophyses short; corona absent, fibula present; parameres subtriangular, with subapical "tooth"; phallobase large, as long as wide. The present publication of the new species is registered in the ZooBank Life Science Identifier with the following LSID code: urn:1sid:zoobank.org:pub:711115ED-E055-4CE28219-2F0831D6CA77.

Description. Holotype male. Body subrectangular, moderately convex. Length: $3.10 \mathrm{~mm}$; greatest width $1,10 \mathrm{~mm}$ (at posterior third of elytra).

Color (Figs. 1-3): cuticle shiny, brownish testaceous with a greenish metallic lustre on dorsal surface. Plastron formed by golden setae covering: a narrow strip at each side of mentum and submentum (setae reaching the third palpomere); hypomeron entirely; sides of prosternum, mesoventrite and 

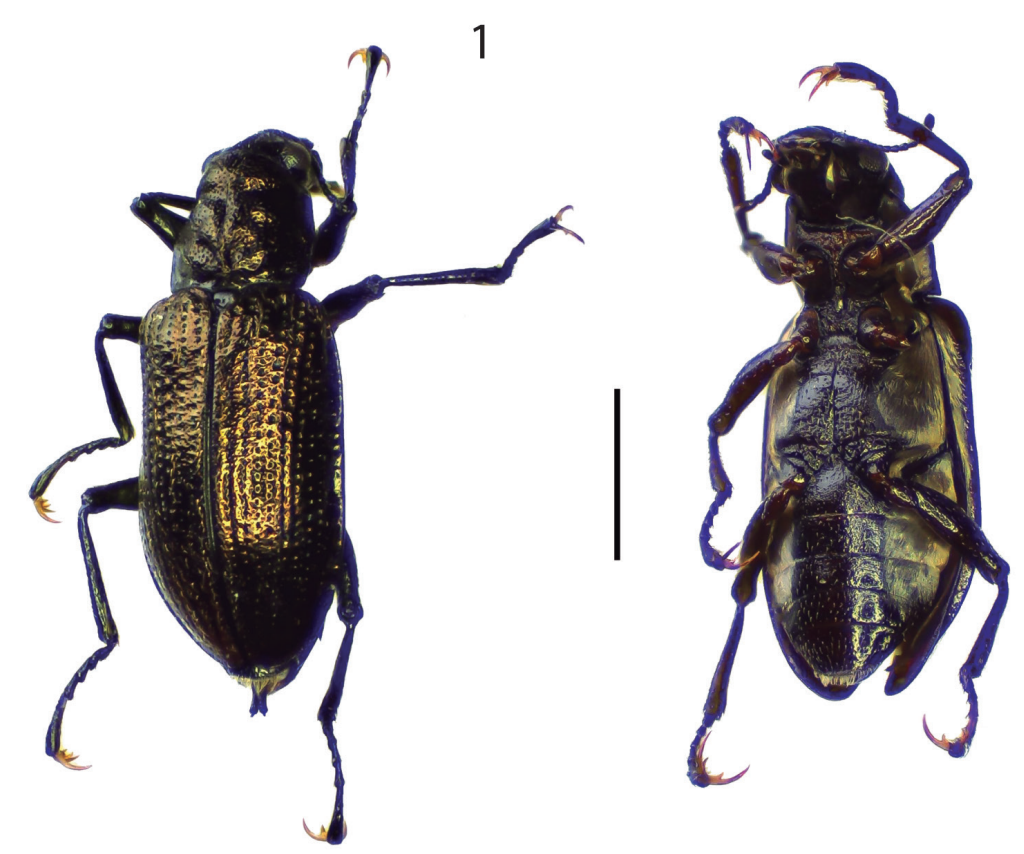

2

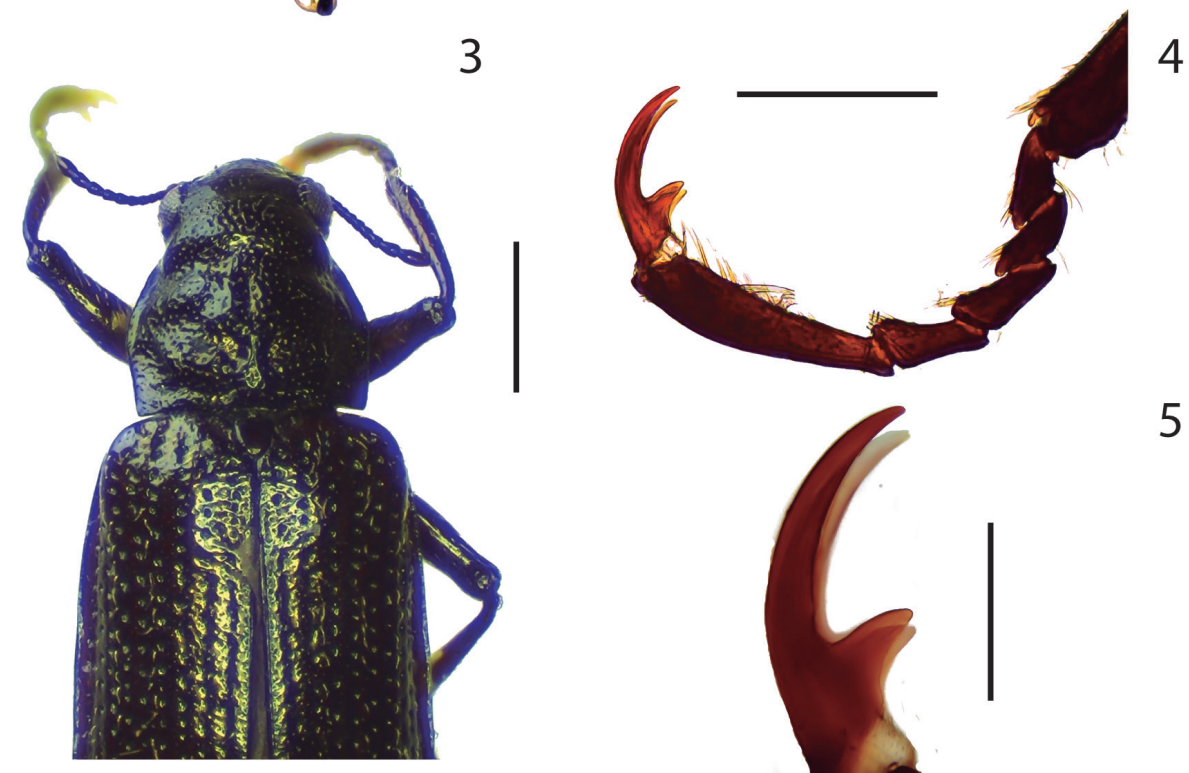

Figures 1-5 - Stethelmis shepardi sp. nov. adult. (1) dorsal habitus; (2) ventral habitus; (3) detail of pronotum; (4) detail of leg; (5) detail of leg tarsal claw. Scale bars: Figs. 1-2: 1 mm; Fig. 3: 0.50 mm; Fig. 4: 0.25 mm; Fig. 5: $0.1 \mathrm{~mm}$.

metaventrite; epipleura (tomentum reaches the first ventrite); inner surface of coxae, trochanter and tibiae, anterior regions of femora; sides of ventrites I-III and basal fourth of sides of ventrite IV.

Head: partially retractable, prognathous, surface punctated, punctures with long golden setae, separated by $1 \frac{1 / 2}{2}-3$ times their diameter, less densely distributed on disc, slightly larger than facets of eyes. Clypeus sculptured as head, frontoclypeal suture straight; labrum subrectangular, with anterolateral angles rounded and anterior margin slightly convex, punctuation similar to that of head, with rows of long golden setae on anterior and lateral margins of ventral region that exceed the limits of the labrum. Antennae 11-segmented, 
filiform, shorter than pronotum, last antennomere the longest, with a cluster of short subapical setae.

Pronotum (Fig. 3) (length $0.70 \mathrm{~mm}$; greatest width, at midlength of pronotum: $0.80 \mathrm{~mm}$ ); wider at base; anterior margin, slightly arcuate, lateral margins smooth, not crenate, curved at midline; anterolateral angles not acute, posterolateral angles short and acute, base trisinuose. Pronotum with two basal oblique oval depressions at each side of midline, one T-shaped depression (transversal branch is on apical third and extends all the width of pronotum, longitudinal branch starts at basal third) and two depressions near posterolateral angles; surface between punctures at depressions of pronotum glabrous. Surface densely punctated, punctures larger than facets of eyes, separated by $1-1 \frac{1}{2}$ times their diameter. Prosternum, short, narrower than 3 times the width of procoxa, prosternal process longer than wide, half the length of procoxal cavities, apex rounded, with a depression along its length, surface microreticulated with disperse setae. Mesoventrite with a groove for reception of prosternal process, concave between mesocoxae, surface as that of prosternum. Metaventrite with a median longitudinal line, sculptured as pronotum.

Legs (Figs. 4-5): surface densely punctate and pubescent, punctures smaller than facets. All tibiae with long golden decumbent setae. Proand mesocoxae globular, metacoxae transverse. Mesotibiae with a cluster of long golden seta on apical fifth of lateral inner face. Tarsi 5-segmented, with a line of ventral setae, the ones on the fifth tarsomere the longest; fifth tarsomere the longest; tarsal claws with a long acute basal tooth.

Elytra: more than twice as long as pronotum; without sublateral carinae, lateral margin smooth; apices rounded and slightly dehiscent. Surface smooth, with disperse short and golden setae; ten striae formed by large punctures separated by 2 times their diameter, elytral intervals of disc with long golden setae arranged in well-defined lines. Scutellum subpentagonal, longer than wide.
Abdomen: surface of ventrites punctate, punctures as wide as facets of eyes, separated by 2-3 times their diameter; disc of ventrite I depressed near the anterior margin; disc of ventrites II-V convex; apex of fifth ventrite rounded, apical margin with short golden setae.

Male genitalia (Fig. 6): Median lobe broad, lanceolate, stretching near apical third, apex acute, lateral margins not parallel, basolateral apophyses short, 7 times shorter than median lobe; corona absent, fibula present. Parameres subtriangular, slender apically, each one with a subapical tooth. Phallobase large, as long as wide, 1.7 times shorter than median lobe.

Female: externally similar to male.

Etymology. The new species is named after Ph.D. William D. Shepard who has always been selflessly generous with us sharing material and useful information about Stethelmis and other elmid genera.

\section{Stethelmis shepardi sp. nov. mature larva}

Body (Figs. 8-10) elongate, slightly flattened dorsoventrally, widest at thorax, abdominal segments narrowing towards posterior end; body subtriangular in cross-section. Thorax and abdomen with dorsal setose gibbosities, larger and more evident in abdomen. Color reddish brown. Length: 5.20-6.40 mm; maximum width: 0.90$1.00 \mathrm{~mm}$.

Head capsule (Fig. 11) exposed, anterior margin with tooth between base of antenna and clypeus, tooth reaching the clypeal margin. Surface covered with large, spherical setiferous tubercles, more densely clustered on disc, and several setae distributed as follows: a group of short slender setae on side of parietale; two long setae on basal third on each side of frontal lines; several long slender setae surrounding stemmata; short ramose setae on anterolateral margin, on each side of frontal line, near base of antenna; a row of ramose setae on 


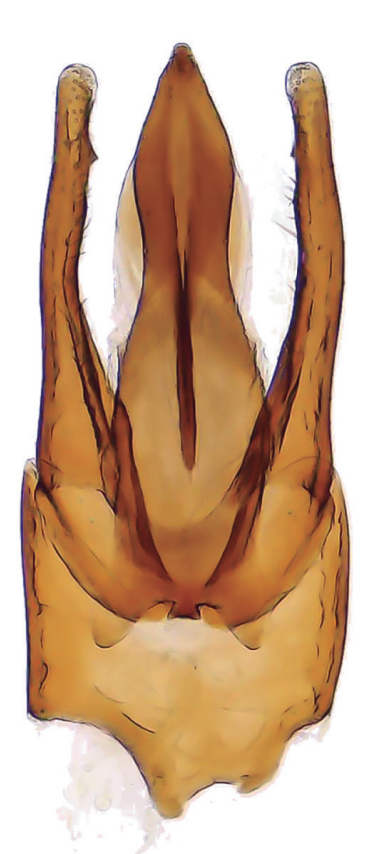

6

Figures 6-7 - Male genitalia of Stethelmis spp. (6) aedeagus of Stethelmis shepardi; (7) aedeagus of Stethelmis kaszabi. Scale bars: Figs. 6-7: $0.25 \mathrm{~mm}$.
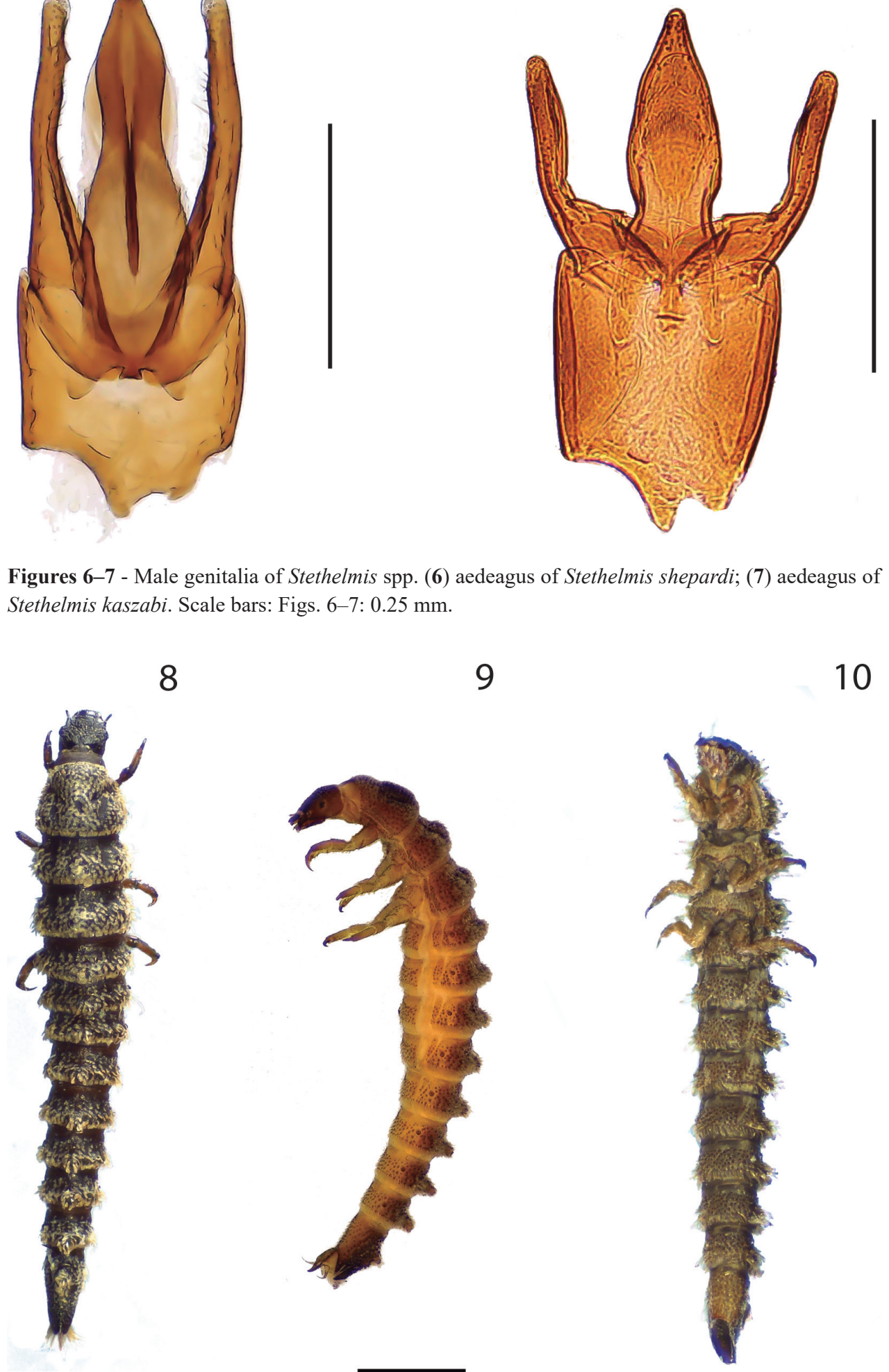

9

10

Figures 8-10 - Stethemis shepardi mature larva, habitus. (8) dorsal view; (9) lateral view; (10) ventral view. Scale bar: Figs. 8-10: $1 \mathrm{~mm}$. 
anterior margin, near frontoclypeal suture and two large ramose setae on clypeal lateral margins, at base of anterior teeth. Coronal line very short and broad, frontal lines long, extending to inner margin of antennal sockets. Frontoclypeal suture feeble; clypeal margin smooth, slightly convex. Gula (Fig. 12) subtrapezoidal, slightly wider than maxillolabial complex; basal margin wider and concave, distal margin narrower and convex; gular sutures poorly defined. Five stemmata on each side of head behind base of antennae.

Labrum (Figs. 14, 16) subrectangular, somewhat wider in anterior third; anterior margin slightly convex, anterolateral margins rounded, each with a row of three strong dorsal setae, outer two ramose, inner one stout and blunt; dorsal surface with two transversal rows of strong ramose setae arranged on anterior third. Ventral surface with anterior row of ramose setae, rest of ventral surface covered by short pubescence oriented mediad and posteriorly.

Antennae (Fig. 17) short, three-segmented, located on anterolateral corners of head capsule. Basal antennomere short, conical, wider than long, apically with a crown of ramose setae; second antennomere the longest, cylindrical, with a few short distal setae, bearing a sensorium subequal in length to third antennomere. Third antennomere the shortest, bearing a long apical seta.

Mandibles (Fig. 15) symmetrical, subtriangular, longer than wide. Apex with three blunt teeth. Dorsal surface with inner margin straight and sharp. Ventral surface with inner margin slightly concave, bearing a comb of long stout submarginal setae. Inner margin of mandible with long plumose prostheca; outer margin with two ramose setae close to midlength.

Maxillae (Figs. 12, 13) with short cardo, irregularly suboval, more or less transverse, 1.252.5 times wider than long, with small ramose seta close to anterior margin. Stipes the largest part, subrectangular, 2.35-3.04 times as long as wide, surface with several setae distributed as follows: a group of four tufted setae near posterior margin, several ramose setae dispersed on disc of stipes, a group of setae on anterolateral outer corner, near palpus (one posterior long slender seta and two anterior large ramose setae) and one small ramose seta between bases of lacinia and galea. Lacinia and galea well developed; lacinia subtriangular, fused to stipes, with inner margin bearing a group of stout setae; galea shorter than lacinia, elongate, with several apical setae. Palpus with four palpomeres, first palpomere the shortest, wider than long, second and third palpomeres slightly narrower, subequal in length, last palpomere slightly longer, narrower; first palpomere bearing one outer ramose seta, third palpomere with two setae, one on each anterolateral corner, last palpomere bearing several short apical setae and sensoria.

Labium (Figs. 12, 13) large, subdivided into a large postmentum and a short prementum, forming together with maxillae the maxillo-labial complex; postmentum subrectangular, 1.63-1.72 times as long as wide, ventral surface with several short ramose setae at each side of midline, distal corners each with one long stout seta and two shorter blunt conical setae. Prementum short, poorly sclerotized, wider than long, distal margins densely setose; palpus with two palpomeres, basal palpomere slightly shorter, distal palpomere with several distal setae and sensoria.

Thorax (Figs. 18-21) strongly sclerotized; notal plates with sagittal lines. Prothorax the largest segment, wider basally; pronotal plate subtrapezoidal, anterior corners rounded; notal plate with two oblique depressions, starting near the sagittal line and ending near the posterolateral margin; ventral region with seven sclerites: one large and irregularly shaped transverse anterolateral pair, one small, triangular lateral pair, one large subtrapezoidal posterolateral pair and one small suboval central sclerite; coxal cavities open. Meso- and metathorax shorter than prothorax; each 

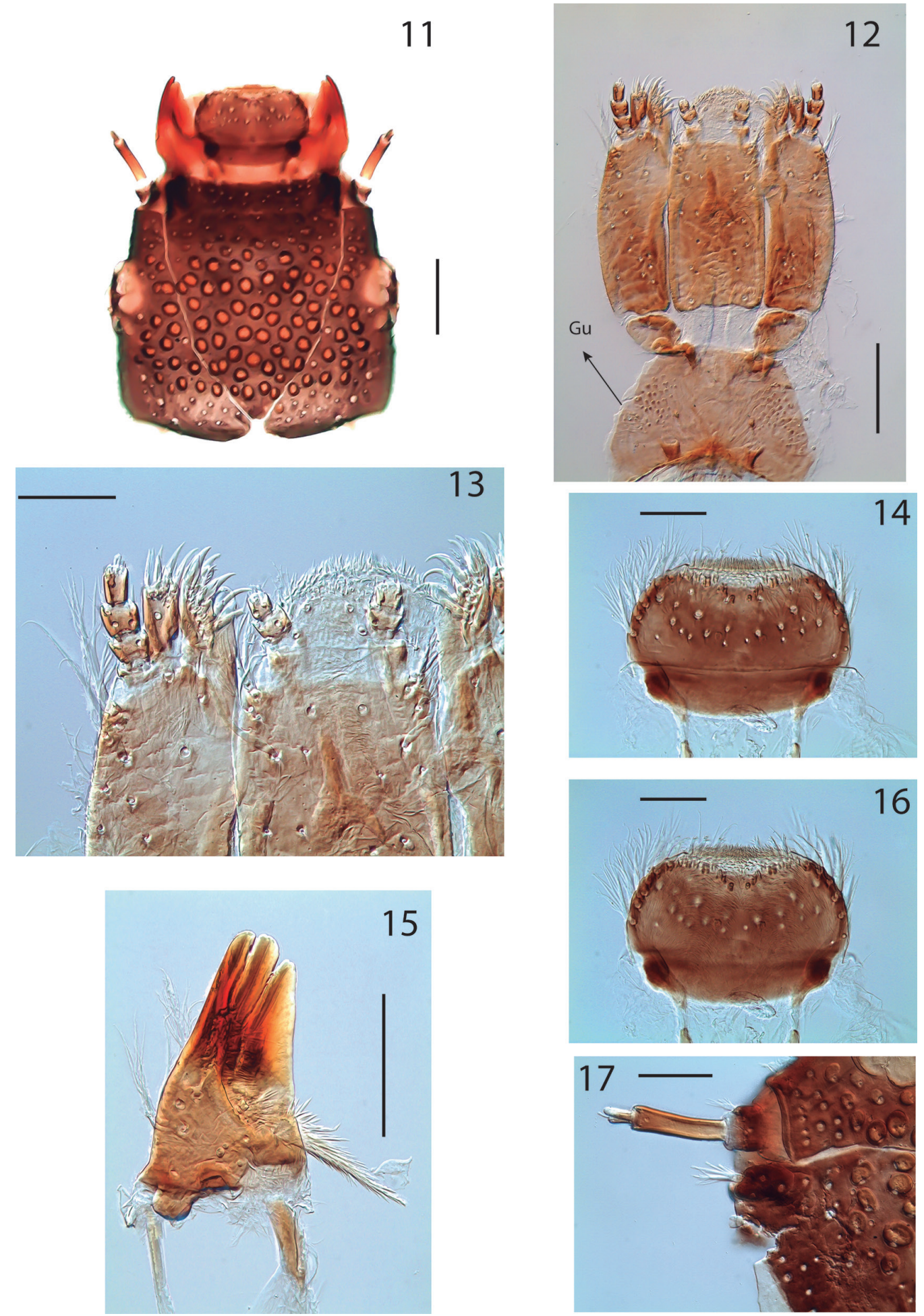

Figures 11-17 - Stethemis shepardi mature larva. (11) head capsule, dorsal view; (12) maxillo-labial complex and gula, ventral view; (13) detail of maxillo-labial complex showing distal end of right maxilla and labium; (14) labrum, dorsal view; (15) left mandible, dorsolateral view; (16); labrum, ventral view; (17) antennae, dorsal view. Scale bars: Figs. 11-12, 15: 0.10 mm; Figs. 13-14, 16-17: 0.05 mm. Abbreviation: Gu- gula. 
18

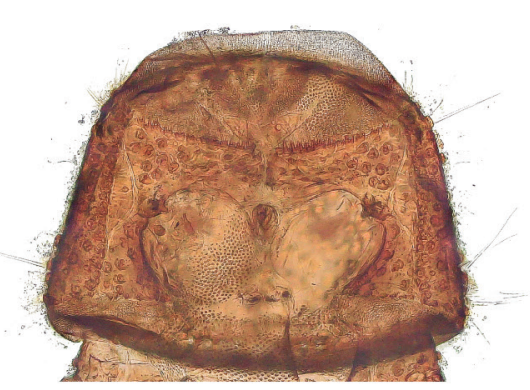

20

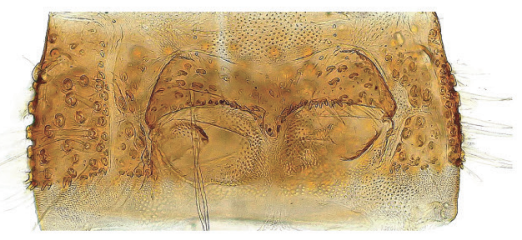

22

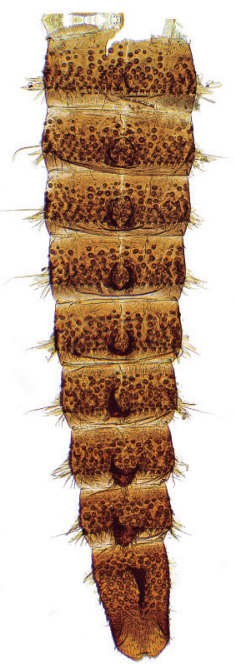

23

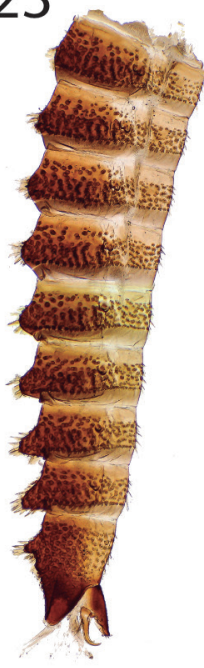

19

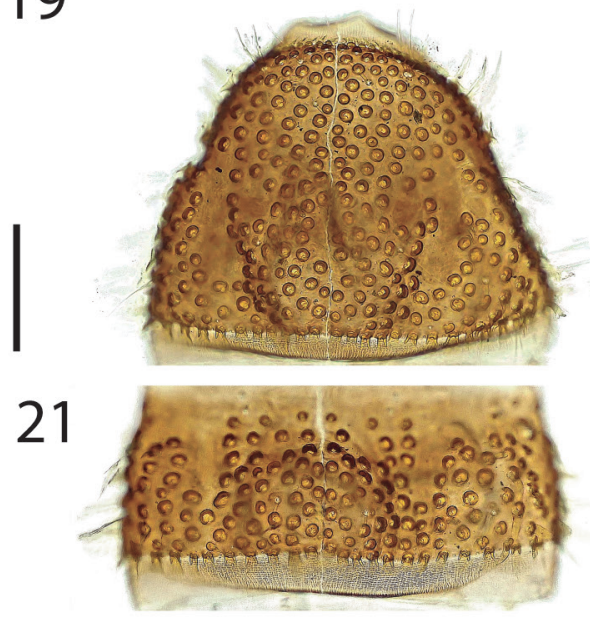

24
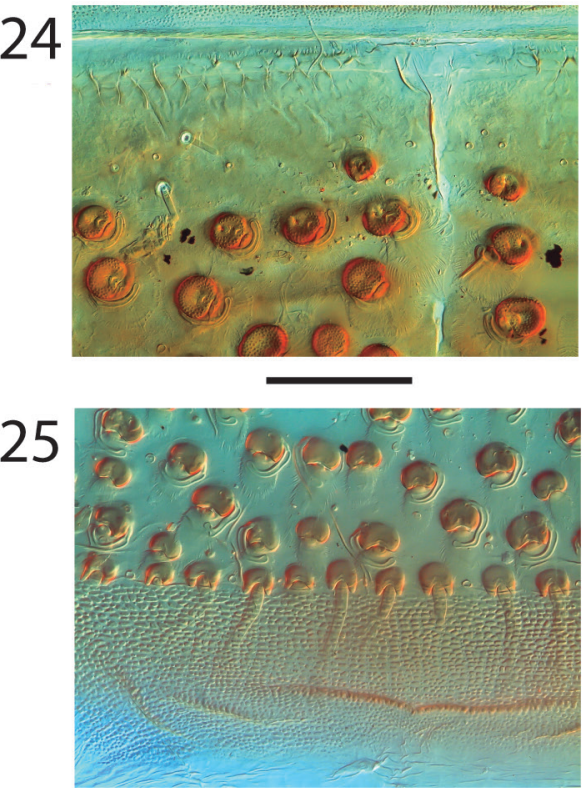

27

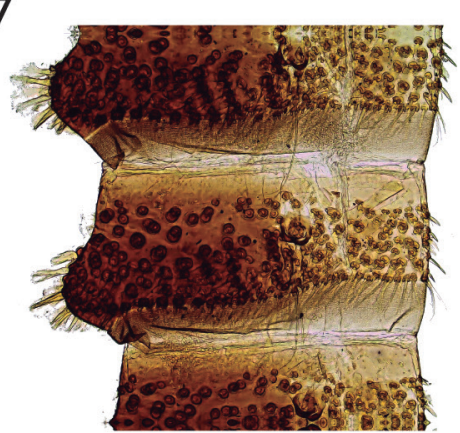

Figures 18-27 - Stethelmis shepardi mature larva. (18) prothorax, ventral view; (19) prothorax, dorsal view; (20) mesothorax, ventral view; (21) mesothorax, dorsal view; (22) abdomen, dorsal view ; (23) abdomen, lateral view; (24) detail of basal portion of the fourth abdominal segment, dorsal view; (25) detail of distal margin of the fourth abdominal segment, ventral view; (26) detail of fifth abdominal segment, dorsal view; (27) detail of fifth abdominal segment, lateral view. Scale bars: Figs. 18-21, 26-27: Figs. 24-25: 0.10 mm. 

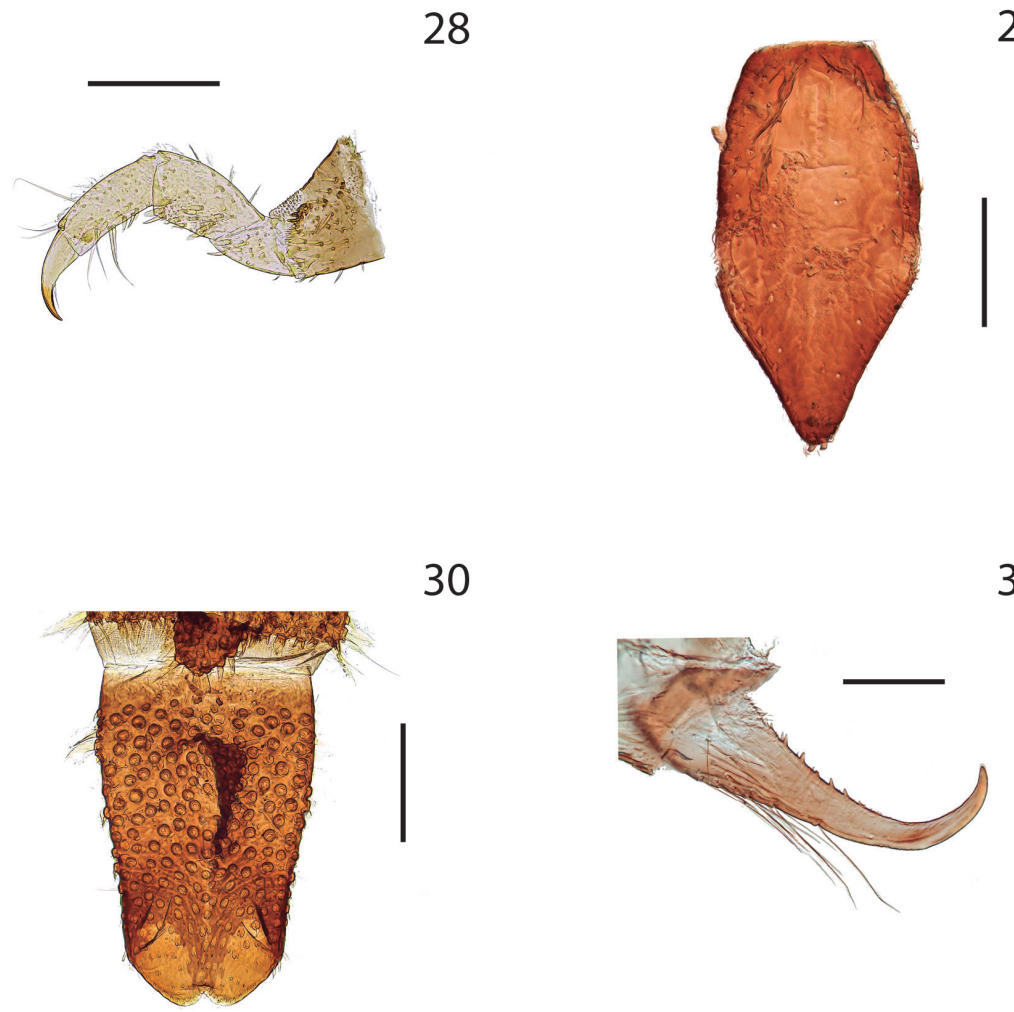

Figures 28-31 - Stethelmis shepardi mature larva. (28) prothoracic leg; (29) operculum of ninth abdominal segment, ventral view; (30) ninth abdominal segment, dorsal view; (31) anal hook of opercular chamber. Scale bars: Figs. 28, 30: 0.25 mm; Figs. 29, 31: $0.10 \mathrm{~mm}$.

segment ventrally with five sclerites: one large anterior subpentagonal sclerite, and two smaller subrectangular sclerites on each side; coxal cavities open. Legs (Fig. 28): with five sections; coxa the largest segment, subtriangular; trochanter smaller, subtriangular; femur and tibia elongate, femur slightly longer and wider than tibia; claw stout, slightly shorter than tibia; surface with several short spines.

Abdomen (Figs. 22-27, 29-31) well sclerotized, composed of nine segments, tapering towards posterior end; segments I-III with complete sagittal line, segments IV-VII with incomplete sagittal line, interrupted by dorsal gibbosities; segment IX the longest. Tergal plates with dorsal gibbosities on disc. Surface of all segments with randomly arranged spherical tubercles. Basal area, near anterior margin, of tergal plates of all segments glabrous with very few spines. Lateral margin with a group of long plumose setae. Posterior margin of tergal and sternal plates of segments I-IX with setiferous tubercles bearing a long plumose seta. Pleural sclerites present on segments I-V; sterna of segments I-VII subrectangular, wider than long. Segment IX elongate, 1.58-1.66 times as long as previous segment, without dorsal keel, ventrally with several spines on distal half; sternal area with apical gill chamber, operculum subpentagonal, distal end smoothly pointed with several strong and ramose setae externally and marginal sharp spines internally, covering a pair of strong distal hooks with inner margin smooth and bearing several long setae on outer margin. Spiracles present on segments I-VIII.

Types. Holotype, male Chubut Province, Esquel city, La Hoya recreational ski center, La Hoya 


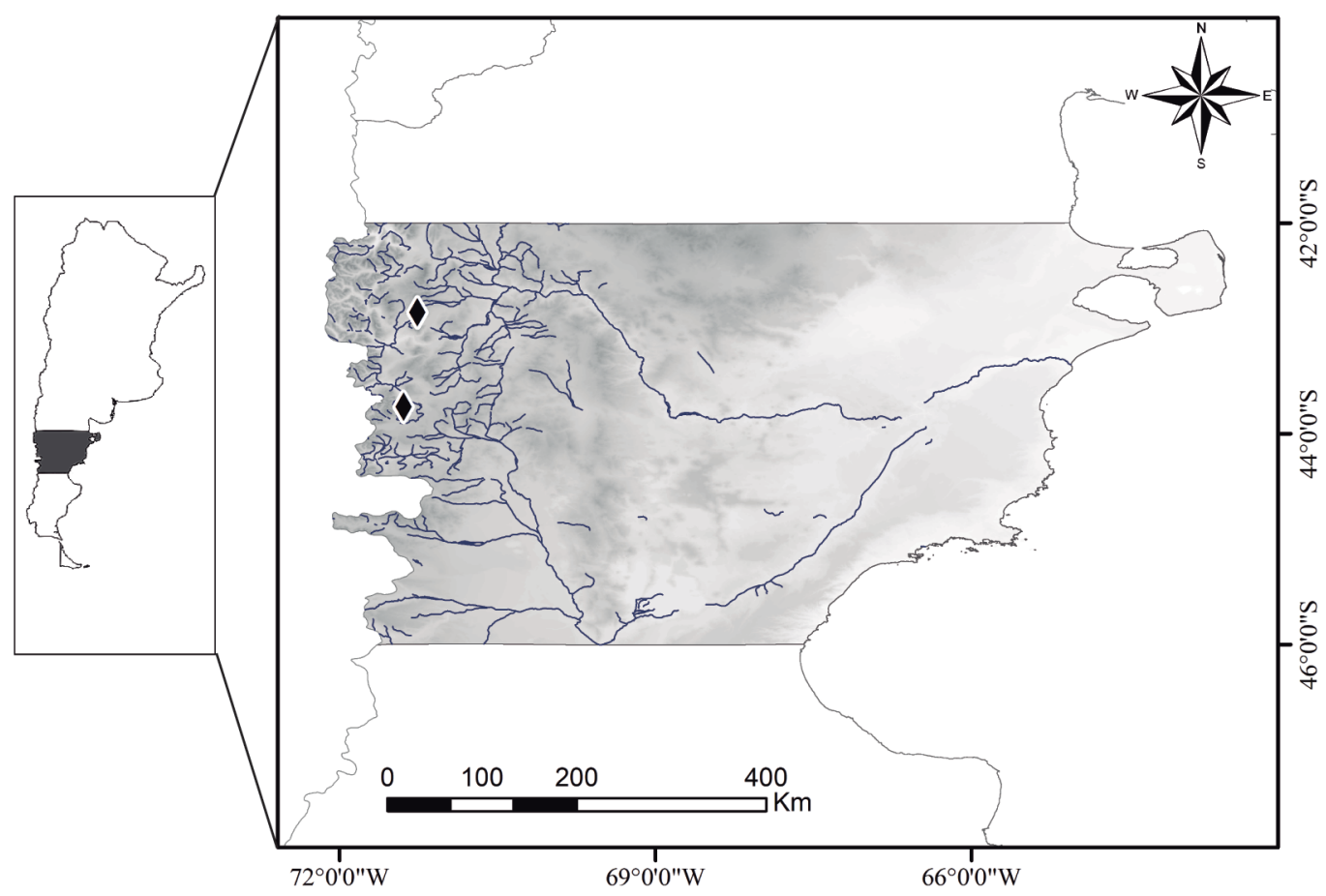

Figure 32 - Distribution map of Stethelmis shepardi sp. nov.

creek, 4250'52.70”S, 71¹5'38.72”'W, 19-I-2017, 1165 m, N. Martínez Román leg. Paratypes (5):1 female Chubut province, Argentina. $32 \mathrm{~km} \mathrm{~S}$ from Corcovado town, at intersection with provincial road 44, Comisario creek, 434' 42.36”'S, 71²3'32.82”W, 760m, 14-III-2017, N. Martínez Román leg.; 1 specimen, same locality, 12/X/2007, P. Pessacq leg.; 2 females, same locality, 8/IV/2009, P. Pessacq leg., 1 female, same locality, V/2005, M. Archangelsky leg.

Larval Material examined. 11 specimens, Chubut province, Argentina. $32 \mathrm{kmS}$ from Corcovado town, at intersection with provincial road 44, Comisario creek, 4344'42.36”'S, 71²3'32.82”W, 760m, 12/X/2007, 8/IV/2009, P. Pessacq leg.; 11 specimens, same locality, V/2005, IX/2005, III/2006, M. Archangelsky leg.; 11 specimens, same locality, 14/III/2017, 24/III/2017, 22/X/2017, N. Martínez Román leg. 13 specimens, Chubut province, Argentina. Road to La Hoya recreational ski center,
La Hoya creek, 42 ${ }^{\circ} 50^{\prime} 52.70^{\prime \prime} \mathrm{S}, 71^{\circ} 15^{\prime} 38.72^{\prime \prime} \mathrm{W}$, 1165 m,19-I-2017, 22-X-2017, N. Martínez Román leg.

Habitat (Figs. 32-37). La Hoya and Comisario creeks are located in the ecotone between Subantartic forest and the Patagonian steppe phytogeographical provinces. These areas are characterized by a gramineous steppe that becomes mixed with a Nothofagus spp. forest (León et al. 1998).

La Hoya creek is a $2^{\text {nd }}$ order watercourse in the Esquel-Percy river drainage system in the Northwest of the Chubut Province (Patagonia, Argentina). Water velocity varies from 0.55 to $0.83 \mathrm{~m} \mathrm{~s}^{-1}$. Water temperature ranges between 1 and $12^{\circ} \mathrm{C}$. Mean depth is about $22 \mathrm{~cm}$. Substratum is dominated by cobbles and boulders with lower proportions of gravel, sand and pebbles (Epele et al. 2011).

Comisario creek is a $1^{\text {st }}$ order stream in the Carrenleufú-Pico rivers drainage system. Water velocity ranges between 0.10 and $1.66 \mathrm{~m} \mathrm{~s}^{-1}$. Water 

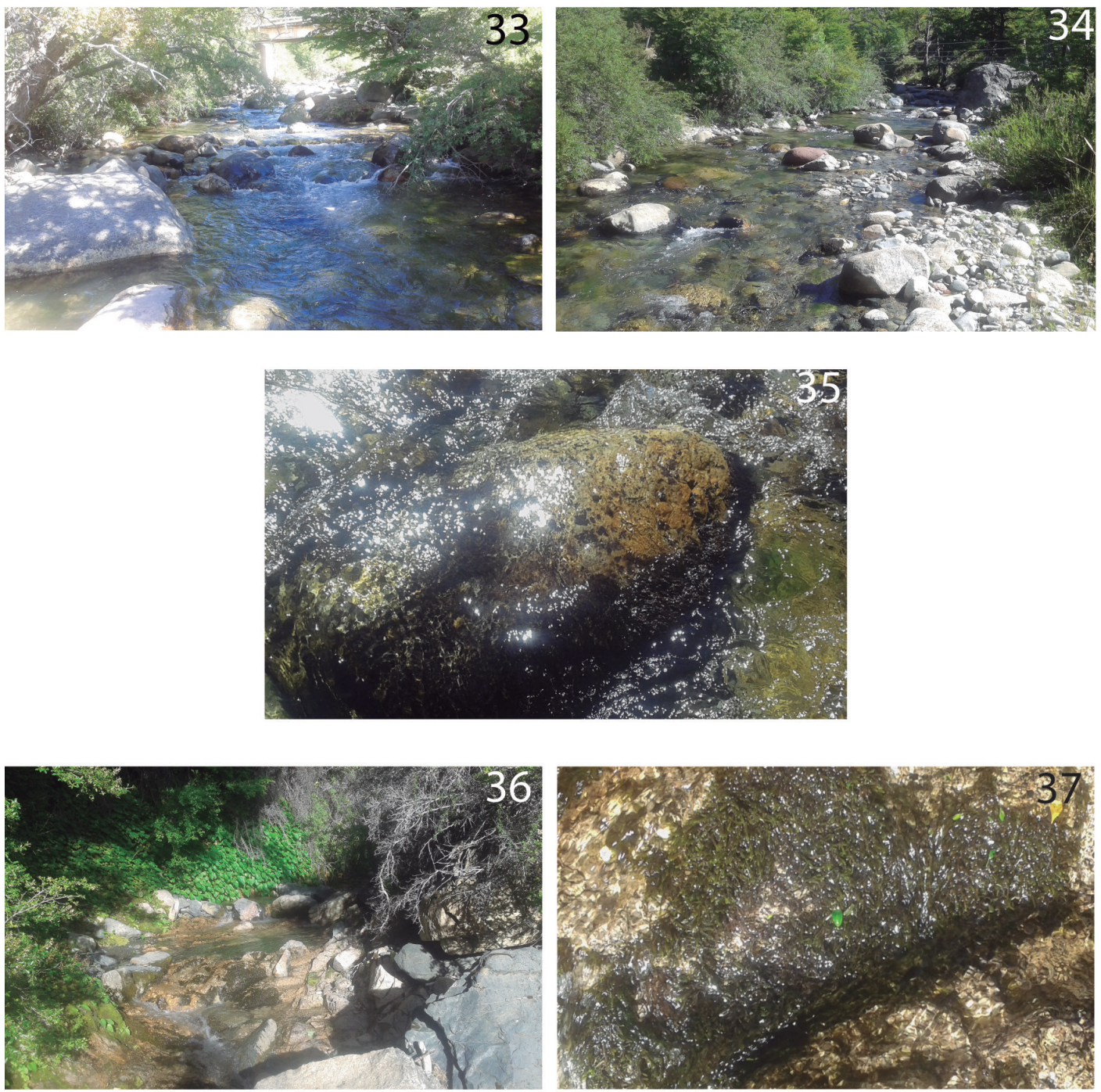

Figures 33-37 - Creek habitats of Stethelmis shepardi sp. nov. (33) and (34) Comisario creek; (35) and (37) boulder covered by bryophytes in Comisario and La Hoya creeks, respectively; (36) La Hoya creek. Photographs by Nicolás Martínez Román.

mean temperature ranges from 1.7 to $7.4^{\circ} \mathrm{C}$. Mean depth is around $25 \mathrm{~cm}$. Substratum is dominated by cobbles and boulders (Miserendino et al. 2011).

In both creeks, adults and larvae were collected almost exclusively on bryophytes attached to boulders that are constantly washed by stream flow. We rarely found the new species on the bottom of the creeks. Specimens of $S$. shepardi cohabit with Luchoelmis cekalovici Spangler and Staines in the same microhabitats. In the creek bed, specimens of Hydora annectens Spangler and Brown and $L$. cekalovici were also found.

\section{Stethelmis kaszabi Hinton, 1970}

To complete the original description of $S$. kaszabi Hinton we include a diagnosis of this species. We also add a description and an illustration of the male genitalia for the first time (Fig. 7).

\section{DIAGNOSIS}

Adults of this species may be distinguished from all the other known Stethelmis species by the following combination of characters:1) areas between punctures at depressions of pronotum glabrous; 2) tomentum on epipleura reaching the 
middle of the third abdominal ventrite; 3) ventrite IV without a basal belt of tomentum; 4) aedeagus as is described below.

Male genitalia: (Fig. 7). Median lobe, broad, longer than parameres, subconical with a basal constriction, apex rounded, lateral margins subparallel, basolateral apophyses short, 4 times shorter than median lobe; corona present, fibula absent. Parameres subtriangular, slender apically without subapical tooth. Phallobase large, 1.55 times as long as wide, 1.21 times shorter than median lobe.

\section{KEY TO MALES OF THE GENUS Stethelmis}

1- Length less than $3 \mathrm{~mm}$, surface between punctures at depressions of pronotum microreticulated, all epipleura with tomentum (except apex) ...Stethelmis chilensis (Chile) - Length more than $3 \mathrm{~mm}$, surface between punctures at depressions of pronotum glabrous, tomentum on epipleura reaching the I or II ventrite ... 2

2- Ventrite IV with a basal belt of tomentum, middle tibiae with a short apical fringe of tomentum. Median lobe of aedeagus lanceolate and parameres with subapical "tooth" (Fig. 6) ... Stethelmis shepardi sp. nov. (Argentina)

- Ventrite IV without tomentum, middle and hind tibiae each with an apical fringe of tomentum. Median lobe of aedeagus subconical and parameres without subapical "tooth" (Fig. 7) ... Stethelmis kaszabi (Argentina)

\section{DISCUSSION}

Complete comparative notes among Stethelmis species are difficult to perform since in the original descriptions, although very detailed, the male genitalia is not described. In the description of $S$. chilensis neither comments on morphology nor illustrations of male genitalia were included and the description of $S$. kaszabi was based on a female. The specimens we identified as Stethelmis kaszabi has all the diagnostic characters stated by Hinton: the size of our specimens range between $3.05-3.20$, the surface of the pronotal impressions are smooth, the plastron on epipleura reaches the first abdominal ventrite and the abdominal plastron is restricted to the first three ventrites. The male genitalia of Stethelmis shepardi sp. nov. is very different from that of $S$. kaszabi (Figs. 6, 7). The median lobe of $S$. shepardi sp. nov. aedeagus has lateral margins not parallel, is wider at basal third, it stretches near apical third and the apex is more acute (almost parallel lateral margins, narrower at basal third, not stretching at apical third and apex little rounded in S. kaszabi). The parameres of these two species are quite different too. Stethelmis shepardi parameres are slightly longer and each of them bear a subapical tooth while in $S$. kaszabi the parameres lack this tooth. Also, the length relationship between median lobe and basal piece differs between these two species. The median lobe of $S$. shepardi sp. nov. is 1.7 times longer than phallobase, while in S. kaszabi this ratio is 1.21.

Regarding the external morphology, $S$. shepardi resembles S. kaszabi. Both species are similar in size $(3.05-3.20 \mathrm{~mm}$ vs $3.00-3.20$ $\mathrm{mm}$ ), the tomentum on epipleura reaches the first abdominal ventrite and the surface between punctures at depressions of the pronotum are glabrous. However both species differ in that the tomentum reaches the base of the fourth abdominal segment in $S$. shepardi while in S. kaszabi it only reaches the third abdominal segment.

$S$. shepardi sp. nov. is different from $S$. chilensis in that is larger (length $3.05-3.20$ vs 2.20 $2.50 \mathrm{~mm}$ ), the areas between punctures at pronotal depressions are smooth (microsculptured in $S$. chilensis), the tomentum on epipleura covers until the first abdominal ventrite (epipleura completely tomentose except very near apex in S. chilensis) and the abdominal tomentum reaches the basal 
fourth of the sides of fourth ventrite (sides of fourth ventrite fully tomentose in $S$. chilensis).

The only Stethelmis described larva until this contribution is the one of $S$. kaszabi. Larvae of $S$. shepardi differ from those of $S$. kaszabi in that they are slightly narrower (ratio length/width 4.50-6.74 vs. $4.08-4.17 \mathrm{~mm}$ ), but the most conspicuous differences are related to the dorsal surface of the body. Stethelmis shepardi sp. nov. larva has large dorsal setiferous gibbosities on the thoracic and abdominal tergites while $S$. kaszabi lacks these gibbosities and has small dark glabrous body tergites. There are also differences in the length of the frontal teeth (between base of antennae and clypeus); in S. shepardi the teeth reach the clypeal margin while in $S$. kaszabi exceed it.

\section{ACKNOWLEDGMENTS}

The authors deeply thank Dr. William Shepard for sharing information about Chilean Stethelmis and Mg. Marcela González Córdoba for her disinterestedly help with the confection of the distribution map. We also are grateful to Dr. Pablo Pessacq for providing us with adult and larval material of the new Stethelmis species. Martínez Román thanks the National Council of Scientific and Technical Research (CONICET, Argentina) for an internal fellowship. This is scientific contribution number 145 from LIESA.

\section{AUTHOR CONTRIBUTIONS}

NRMR and MA performed the fieldwork; NRMR and VM performed most of the morphological studies on adult specimens; MA and NRMR performed most of the larval studies; NRMR and MA were in charge of the photographic documentation; all authors took part on the preparation of the manuscript.

\section{REFERENCES}

ARCHANGELSKY M AND MANZO V. 2007. Descripción de las larvas maduras de los géneros Stethelmis Hinton y Luchoelmis Spangler and Staines (Insecta: Coleoptera, Elmidae). Rev Mus Arg Cien Nat 9: 79-87.

EPELE LB, MISERENDINO ML AND PESSACQ P. 2011. Life history, seasonal variation and production of Andesiops torrens (Lugo-Ortiz and McCafferty) and Andesiops peruvianus (Ulmer) (Ephemeroptera: Baetidae) in a headwater Patagonian stream. Limnologica 41: 57-62.

HADLEY A. 2010. CombineZP public domain image processing software.

HARRISON JDUG. 2012. Cleaning and preparing adult beetles (Coleoptera) for light and scanning electron microscopy. Afr Entomo 20: 395-401.

HINTON HE. 1945. Stethelmis chilensis, new genus and species of Elmidae from Chile (Coleoptera). P Roy Entomol Soc B 14: 73-76.

HINTON HE. 1970. Zoological results of Gy. Topal's collectings in South Argentine. 21. A second species of Stethelmis (Coleoptera: Elminthidae). Acta Zool Hung 16: 109-113.

KODADA J, JÄCH MAAND ČIAMPOR JR F. 2016. Elmidae. In: Beutel RG and Kristensen NP (Eds), Coleoptera, Volume 1: Morphology and Systematics (Archostemata, Adephaga, Myxophaga, Polyphaga partim). Arthropoda: Insecta, Handbook of Zoology. Walter De Gruyter, Berlin/ Boston, p. 561-589.

LAWRENCE PA. 1991. Coleoptera. In: Stehr F (Ed), Immature Insects Vol. 2. Kendall/Hunt, Debuque, Iowa, p. 144-183.

LEÓN RJC, BRAN D, COLLANTES M, PARUELO JM AND SORIANO A. 1998. Grandes unidades de vegetación de la Patagonia extra andina. Ecol Aust 8: 125-144.

MANZO V. 2013. Los élmidos de la región Neotropical (Coleoptera: Byrrhoidea: Elmidae): diversidad y distribución. Rev Soc Entomo Arg 72: 199-212.

MANZO V AND ARCHANGELSKY M. 2014. Elmidae. In: Roig Juñent $\mathrm{S}$ et al. (Eds), Biodiversidad de Artrópodos Argentinos, Vol. 3. Universidad Nacional de Tucumán, Tucumán, ARG, p. 487-499.

MISERENDINO ML, CASAUX R, ARCHANGELSKY M, DI PRINZIO CY, BRAND C AND KUTSCHKER AM. 2011. Assessing land-use effects on water quality, in-stream habitat, riparian ecosystems and biodiversity in Patagonian northwest streams. Sci Total Environ 409: 612-624.

QGIS DEVELOPMENT TEAM. 2017. QGIS Geographic Information System. Open Source Geospatial Foundation Project.

SOLERVICENS ALESSANDRINI J. 2014. Coleópteros de la Reserva Nacional Río Clarillo, en Chile Central: taxonomía, biología y biogeografía. Corporación Nacional forestal, $478 \mathrm{p}$. 